\title{
The bicycle-train travellers in the Netherlands: personal profiles and travel choices
}

\author{
Olaf Jonkeren ${ }^{1} \cdot$ Roland Kager $^{2}$ (D) $\cdot$ Lucas Harms $^{3} \cdot$ Marco te Brömmelstroet $^{4}$ (D)
}

Published online: 26 October 2019

(c) The Author(s) 2019

\begin{abstract}
The Netherlands seems to exhibit the unique conditions that allow cycling on the country level instead of only the city level. Moreover, the national transit system seemingly provides one crucial condition: citizens use the train and cycling systems in an integrated manner, with combined bicycle-train transport recently demonstrating strong growth. Relatively little is known about bicycle-train users, i.e. the people who combine the bicycle and the train in a single trip. In this paper, we investigate their profiles and travel choices, in terms of the modes they choose for access and egress travel, their choice of stations, and their choice of type of bicycles. Studying this specific group can add to our understanding of the role of the train system in the success of cycling in the Netherlands, in turn helping improve policy transfer to metropolitan areas in other countries. In 2017, in cooperation with the Dutch National Railways, researchers surveyed a sample of train travellers, ultimately resulting in more than 3000 completed questionnaires. Descriptive analyses revealed that, compared to train travellers who do not or rarely cycle to/from train stations, bicycle-train users are on average more likely to be young people who are engaged in fulltime employment or entrepreneurs, commute to work and hold university degrees. As for their cycling behaviour, bicycle-train travellers use bicycles much more often on the homeend of train trips than on the activity-end. Furthermore, bicycle-train travellers infrequently use suburban stations on the home-end, preferring large stations in the centres of major cities instead. For those who use bicycles, shared bicycles claim a considerable share on the activity-end of a train trip.
\end{abstract}

Keywords Bicycle-train · Bicycle $\cdot$ Transit $\cdot$ Train $\cdot$ The Netherlands

Marco te Brömmelstroet

M.C.G.teBrommelstroet@uva.nl

1 KiM - Netherlands Institute for Transport Policy Analysis, Bezuidenhoutseweg 20, 2594 AV The Hague, The Netherlands

2 Studio Bereikbaar, Stationsplein 45, 3013 AK Rotterdam, The Netherlands

3 Dutch Cycling Embassy, Molengraaffsingel 10, 2629 JD Delft, The Netherlands

4 Centre for Urban Studies, Urban Cycling Institute, University of Amsterdam, Nieuwe Achtergracht 166, PO Box 15629, 1001 NC Amsterdam, The Netherlands 


\section{Introduction}

Cycling, especially in relation to urban mobility, has experienced a strong surge of academic interest in recent years (Fishman 2016). While most studies examine cycling environments in the North American context, increasingly academic and policy attention has turned to the Netherlands, which offers a context where cycling is a more mature, mainstream mode of transport (e.g. Harms et al. 2014, 2016; Rietveld and Daniel 2004; NelloDeakin and Harms 2019).

However, most of these studies have a critical blind spot: they largely study cycling as a stand-alone transport mode and/or on the level of cities or neighbourhoods. The limitations of solely examining this geographical scale is also an oft-cited research limitation of papers about cycling environments. This is seemingly a fundamental limitation, especially in the Netherlands. In the Dutch context, certain urban cores have local modal splits for cycling of above $50 \%$, but high cycling levels are not only confined to cities, as evidenced by cycling's $25 \%$ modal share on the national level (Harms et al. 2014). Hence, the Netherlands' favourable conditions allow cycling to function on the scale of an entire country of 17 million people (PBL 2016). Arguably, the Dutch case can provide relevant lessons about the necessary conditions for mainstreaming cycling in sprawling urban regions around the world.

On this geographical scale, the proliferation of bicycle use is aided by the Dutch national transit system. Although the train and cycling systems are originally not necessarily integrated by design, their combination has created a new type of traveller-the bicycletrain user. A bicycle-train traveller is defined as someone who combines the use of the bicycle and the train in a single trip. Most bicycle-train travelers use a private bike which is parked in a bicycle parking facility at the train station, a shared bike which is retrieved from and returned to a facility at the train station, or a folding bike which can easily be taken on board of the train. Very few people take their regular, non-foldable, bike on board the train. ${ }^{1}$

Consequently, it has been argued that large parts of the cycling and railway system across the Netherlands should be regarded as one distinct transport mode: 'Cycling and public transport can have a symbiotic relationship, forming a hybrid, distinct transport mode' (Kager et al. 2016, p. 208). The relevance of combined bicycle-train transport can be illustrated by the fact $11 \%$ of all trips of more than $15 \mathrm{~km}$ are train trips in the Netherlands and that $83 \%$ of all train journeys are multimodal trips. ${ }^{2}$ In addition, combined bicycle-train transport is experiencing strong growth in the Netherlands, with the number of train passenger kilometres increasing by $21 \%$ between 2005 and 2016 . This increase is accompanied by the growth of cycling in the modal split at the home-end of the train trip, from $36 \%$ in 2005 to $43 \%$ in 2016 . At the activity-end this share rose from 10 to $14 \%$ (Jonkeren et al. 2018).

The system characteristics and ramifications of the bicycle-train system are increasingly being studied, both in academic research and in policymaking. See for example Jonkeren et al. (2018), Kager and Harms (2017), Geurs et al. (2016), and Lee et al. (2016). The focus of Jonkeren et al. (2018) is on bicycle parking at railway stations, Kager and Harms (2017)

\footnotetext{
${ }^{1}$ Less than $2.5 \%$ of the total number of bicycle-train travelers in our sample belongs to this last group.

2 Derived from the Dutch National Household Travel Survey, the percentages are an average for the period 2011-2013. As train trips are usually made over relatively long distances, the share of train trips in the total number of trips is calculated for distances of more than $15 \mathrm{~km}$.
} 
and Lee et al. (2016) discuss the benefits of improving the integration of cycling and transit, and Geurs et al. (2016) examine the impacts of bicycle-train integration policies on train ridership and job accessibility.

Nevertheless, relatively little is reported about the people who use the combined bicycle-train mode. Many studies to date have targeted either cyclists (e.g. Menghini et al. 2010) or transit travellers (e.g. dell'Olio et al. 2011). This paper presents the analysis of a large-scale questionnaire that was specifically devised to bridge this gap and investigate who the bicycle-train travellers are and how they use the system. Studying this specific group will shed light on the key role that the train system plays in the success of cycling in the Netherlands, although a relatively small number of bicycle trips is directly linked to a train trip. The reasoning is that once a traveller can rely on the bicycle and train for longer distance trips, the bicycle arguably becomes a more suitable mode for local trips. Thus, the presence of a high quality train service can be seen as an important prerequisite for local cycling.

The next section of this paper presents an overview of the academic literature on combined use of cycling and transit. We then outline the survey data and methodological choices, followed by a discussion of the results, presented in two separate parts. The first part explores the profile of the bicycle-train users and their key characteristics, comparing them to other train users. The second part examines their behaviour, zooming in on their choice of stations, trip chaining, modes for access and egress travel, and type of bicycles. By focusing on not one but several choices (most bicycle-train studies only examine access and egress mode choices), we are able to provide a more complete picture of the bicycletrain traveller. We close with a discussion of the implications of our findings for research and practice.

\section{Literature review on combined bicycle-train use}

We reviewed two strands of academic literature: (1) conceptual studies that define and characterise bicycle-train use as part of the mobility system, and (2) empirical studies that focus on the use, behaviour and choices of bicycle-train users. Our selection of relevant literature is based on an extended search via multiple online engines, with the digital library from the University of Amsterdam as a starting point. In addition, we applied backward and forward snowballing, focusing the literature search on the features (author, references, citations, keywords, etc.) of a key publication.

\section{Conceptual studies}

Recent conceptual studies increasingly characterise the bicycle-train combination as an integrated transport system, with different characteristics than the sum of its individual parts (Kager et al. 2016; Krizek and Stonebraker 2010). This synergetic characteristic can be explained by the combined strength of both systems. When, for a given trip, a user can personalise the use of speed and accessibility (by for example opting to cycle to a different station than the closest one), the performance is not the average of the bicycle and train characteristics, but rather the sum of those characteristics. In a similar vein, according to Pucher and Buehler (2009) and Kager et al. (2016), the bicycle and train reinforce each other in a largely symbiotic relationship: the bicycle amplifies the range or catchment area of the train system, and the train, in turn, amplifies the range of the bicycle. The integrated 
bicycle-train system offers both speed (for connections between cities) and door-to-door accessibility (for both access and egress trips within cities), and in many, if not most urban constellations, the system can compete with the speed and accessibility of cars.

A recent study by Kager and Harms (2017) elaborated on these synergetic characteristics of bicycle-train use, providing an overview of the various advantages of an integrated bicycle-train system. The following two main advantages were identified:

1. Increased range Assuming an average bicycle speed of roughly three times faster than an average walking speed $(15 \mathrm{~km} / \mathrm{h}$ versus $5-6 \mathrm{~km} / \mathrm{h})$, cycling can theoretically cover a distance that is three times longer. The bicycle, therefore, covers a nine-fold larger catchment area (Fleming 2016). In this way, stations are connected to considerably more households, substantially increasing the potential number of users of these stations, their services and their facilities.

2. Enhanced choice In urban areas where several stations are located within cycling range, travellers can choose between stations. This 'station choice' will depend on the travel destination, the available train services, the facilities at stations, and other factors. More choice improves connections to the various destinations (matching the preferences of more passengers) and increases reliability (in the event of planned or unplanned disruptions). Moreover, this also implies the possibility of circumventing a nearby station that offers a slower train service and instead cycling to a station situated further away that offers faster and/or more frequent connections (Krizek and Stonebraker 2010); thereby increasing access to fast train services.

The first advantage can be summarised as the 'station perspective', in which the same station can attract more travellers that arrive by bicycle. The second advantage can be summarised as the 'user perspective', in which the same user can reach more stations when accessing them by bicycle.

\section{Empirical studies}

In the empirical studies selection, we distinguish between studies focusing on user characteristics including station choice, trip characteristics, and other aspects of combined bicycle-transit use.

There is very little available research on the user characteristics of combined bicycletransit travel, including demographics. A rare exception is the recent study by Shelat et al. (2018), which reveals that bicycle-transit users in the Netherlands are more likely to belong to a higher household income group and are more educated than the overall sample. In addition they identify prototypical bicycle and transit users using Latent Class Cluster Analysis.. The largest groups are university students living with their parents $(22.7 \%)$ and middle-aged, full-time professionals travelling to/from work from urban or suburban regions to highly urbanised areas $(26.5 \%)$. Contrary to the current paper they do not study the choices which are made by the combined bicycle-train user. Research by Givoni and Rietveld (2007) revealed that bicycles are relatively often used on a train journey's accessside by students and people commuting to/from work.

Another branch of the existing empirical research examines the factors underlying the choice of a particular station. Based on data for the Netherlands, Van Nes et al. (2014) found that users prefer to travel via larger stations where express ('intercity') trains stop, even if they are not travelling via an express ('intercity') train. In addition, based on 
a recent survey among 269 bicycle-train users in the Netherlands, using a stated-choice experimental design, Van Mil et al. (2018) concluded that five factors were crucial for travellers' station choices: the total bicycle trip time; the time needed to park the bicycle and walk to the platform (parking time); the bicycle parking costs; the total train trip time; and the number of transfers. Additionally, based on the survey results, Van Mil et al. (2018) derived so-called 'values of time', which help determine the relative importance of the various factors influencing the choice of stations. The research found that the bicycle trip time costs $€ 0.11$ per minute; the parking time (including walking time to platform) $€ 0.08$ per minute; the train time $€ 0.08$ per minute; and the transfer $€ 0.60$. This implies, for example, that travellers are willing to cycle $5.5 \mathrm{~min}$ to a station located further away, in order to avoid a single transfer, equalling $1.2 \mathrm{~km}$ of additional cycling distance (train travel time and parking time being equal).

The third focus of the existing empirical research is on the trip characteristics of combined bicycle-transit travel. Research by La Paix and Geurs (2015) found that perceptions and attitudes also significantly influence the decision whether to cycle to stations (on the access side): the higher the perceived quality of station environments, of parking facilities and of train connections (in terms of frequency and punctuality), the more frequently bicycles are used for trips to/from stations. Givoni and Rietveld (2007) showed that the availability of a car does not automatically make it the first choice of access/egress mode: of all respondents who owned cars, only $16 \%$ chose to use their cars to travel to stations. In addition, they revealed that train passengers who experience improved bicycle parking conditions (both monitored and unguarded) are somewhat more satisfied with their total train trip. Similarly, Brons et al. (2009) found that the extent to which train passengers were satisfied with their total trip was largely determined by the quality of access and egress transport. More specifically, Hoogendoorn-Lanser and Van Nes (2005) found that the access and egress travel to stations accounted for two-thirds of the trip's usefulness (satisfaction) in the perceptions of the travellers, while accounting for half of the total trip time. Train passengers who cycle to/from stations would thus attach relatively high importance to bicycle storage facilities, as well as to the walking and cycling routes involved in the entire trip chain. Additionally, Van Nes et al. (2014) classified the various access and egress modes that can be used in combination with trains, based on the 'resistance' experienced when transferring between these modes and trains. Resistance is measured as the perceived number of extra minutes of travel time due to the transfer. In an urban context the ranking is as follows (from most to least attractive): walking, cycling, metro, car, tram, and bus. The researchers emphasised that every mode transfer is disadvantageous for travellers, and it is preferable to limit the number of mode transfers as much as possible, preferably to only one transfer.

Regarding egress, research by Martens (2007) and Villwock-Witte and Grol (2015) found that the introduction of the Dutch public transport bicycle (PT-bicycle) ${ }^{3}$ resulted in increased train use. Moreover, $15 \%$ of PT-bicycle users indicated that the combination of PT-bicycle and train had replaced trips they had previously made by car. Further, studies by Rietveld (2000) and Keijer and Rietveld (2000) revealed that the limited availability of bicycles at stations on the egress side was a major impediment to train travel to these stations, making travellers more inclined to use other modes of transport (for people who

\footnotetext{
${ }^{3}$ The PT-bicycle ('OV-fiets' in Dutch) is the bike-sharing system of the Dutch National Railways (NS).
} 
routinely travel to the same station, purchasing a 'second' bicycle was a potential mitigation strategy).

Regarding the integrated bicycle-train trip (including both access and egress), according to a literature review based on Dutch- and English-language academic publications by Leferink (2017), the most influential factors for combined bicycle-train use are the access and egress distance, the overall conditions for bicycle and train use (including safe bicycle routes), competition from other modes (such as the car), the share of commuting trips in total trips, and the number of rainy days.

Other empirical research focused on bicycle parking. Recently, Heinen and Buehler (2019) conducted a review of the scientific literature on this topic. Their overall conclusion is that the level of evidence on the importance of bicycle parking is limited. Several general patterns were identified though: (1) greater bicycle parking supply is correlated with more bike parking, (2) cyclists and potential cyclists prefer higher quality bicycle parking facilities over lower quality facilities or no bicycle parking and (3) bicycle parking supply appears to be a determinant of cycling for current and potential cyclists. Turning to several research papers, based on a survey of five smaller stations in the Netherlands, Martens (2007) found that $11 \%$ of respondents were more willing to cycle to stations because of the improved bicycle parking conditions, indicating that improving bicycle parking facilities can increase cycling to/from stations. A case study analysis of 'Bike and Ride' facilities in San Francisco found that both additional bicycle parking facilities and improvements to cycling infrastructure increased demand for cycling-transit use (Cervero et al. 2013). No studies were found that referenced the choice of certain types of bicycles.

In summary, recent studies increasingly characterise the bicycle-train combination as an integrated transport system, with different characteristics than the sum of the individual parts. This synergetic characteristic can be explained by the combined strength of both systems. Most empirical studies, however, focus only on one part of the system, such as travelling to/from the station by bicycle or parking, mandating a deeper investigation of the bicycle-train system, as an integrated mode of transport, and its users.

\section{Data and analysis}

\section{Data}

In cooperation with the Dutch National Railways, a questionnaire was administered under the NS Panel, from 27 March 2017 to 13 April 2017. The NS Panel represents all train travellers in the Netherlands and is an initiative of the Dutch National Railways. The 67,000 members of the NS Panel are asked to complete questionnaires several times a year. The goal of the NS Panel is to improve the service of the Dutch National Railways. The NS regularly cooperates with research institutes and universities to analyse the answers to their questionnaires.

In total 5,557 questionnaires were sent. One week after the respondents had received the questionnaire, a reminder was sent to those who had not yet responded, ultimately resulting in 3063 completed questionnaires (a 55\% response rate). Of this total number of respondents, 764 did not travel by train during the observed two-week period and hence were excluded from the analysis, providing a final sample of 2299 respondents.

Respondents were asked to provide information about their travel behaviour during the two-week period under study. By having the questionnaire span 2 weeks and by requesting 
information about travel behaviour over a relatively long period (instead of one day, for example), we reduced the probability that the observed travel behaviour would deviate from the respondents' normal travel behaviour. Moreover, this reduced the impact of external factors, such as bad weather, illness or interruptions in train services. The dataset derived from the questionnaire was enriched with data about general travel behaviour and personal data (as provided by respondents at the time they joined the NS Panel or updated their profiles). ${ }^{4}$ In total, the dataset contains about 60 variables with information such as the postcode, age and household composition of the respondent, but also car use (not in combination with the train but in general) and trip chaining.

The respondents were approached by email and were requested to fill out an online questionnaire on their computer or smartphone. The questionnaire focused on those respondents in the NS Panel who had previously reported regularly travelling from/to the larger Dutch cities: Amsterdam, Utrecht, Rotterdam and/or Eindhoven. This sampling approach allowed the inclusion of respondents who live all over the Netherlands, with a concentration of residents living in the mentioned cities. ${ }^{5}$ We opted for this approach because the combination of bicycle and train is most frequently used in urban areas in the Netherlands. This was at the same time also the only piece of information we have to base our sampling strategy on. Had the sampling not applied the mentioned focus, it is very likely that a larger proportion of respondents would not have used the combination of bicycle and train in the two-week period, and thus a larger proportion of the sample would not be available for analysis. A sampling limitation was the participation of NS Panel respondents in previous questionnaires and research. Members are given a 'rest period' of about six weeks between surveys, in order to prevent questionnaire fatigue.

The described sampling strategy might be criticized. It has some limitations as a result of the multiplicity of themes covered, the unavailability of an own panel and the lack of relevant earlier work giving directions for sampling. However, since the goal of this paper is to explore several topics (station choice for example) in the field of bicycle-train travel offering a basis for further research on these topics, this is considered an acceptable drawback.

\section{Analysis}

For the analysis of the bicycle-train traveller in the next section, the sample of 2299 respondents was subdivided into three groups, according to their frequency of bicycle use for access/egress:

\footnotetext{
${ }^{4}$ Members of the NS Panel are asked to update their profile four times a year. As this update is not mandatory, not all members complete an update every three months. However, this is not considered a problem because most members' personal data and general travel behaviour do not significantly change every three months. On the basis of the information from the NS Panel and considering the fact that that members are on average quite dedicated to filling out questionnaires (response rate of 55\%), the time between filling out the survey and the last profile update is likely to be relatively short.

${ }^{5}$ The city of The Hague was not included for the following reason: this paper is a spin-off, of a larger research project on bicycle parking at railway stations in the Netherlands. This research project had a spatial focus on those areas (cities) where bicycle parking problems were most severe. The Hague was not one of those cities. We acknowledge that this is a limitation to our research. Of the studied cities, both Utrecht and Eindhoven are characterised by having one large central train station and only a few minor stations in or near the city, whereas both Amsterdam and Rotterdam offer a range of stations, both large and small.
} 
Table 1 Bicycle-train traveller groups

\begin{tabular}{lll}
\hline Frequency of bicycle-train combination & $\begin{array}{l}\text { No. of respond- } \\
\text { ents }\end{array}$ & $\begin{array}{l}\text { No. of cycling days to/from } \\
\text { home-end station in two-week } \\
\text { period }\end{array}$ \\
\hline Not at all or infrequent bicycle-train traveller & 990 & 0.12 \\
Average bicycle-train traveller & 634 & 3.39 \\
Frequent bicycle-train traveller & 675 & 4.14 \\
Total & 2299 & 2.24 \\
\hline
\end{tabular}

- Not at all or infrequent bicycle-train traveller: 0-15\% of total number of trips.

- Average bicycle-train traveller: $16-50 \%$ of total number of trips.

- Frequent bicycle-train traveller: $51 \%$ or more of total number of trips.

The respondents in the latter two groups are classified as 'bicycle-train travellers', while the respondents in the first group are not. The threshold values were chosen so that the sample is divided into roughly three equal parts (by number of respondents). ${ }^{6}$ Table 1 shows that the average bicycle-train group is hardly different from the frequent bicycletrain group but clearly distinguishes itself from the not at all or infrequent group in terms of the average number of days in the two week period on which the bicycle was used to travel to/from the home-end station. This justifies our choice to classify the respondents in the last two groups as 'bicycle-train travellers'.

The dataset contains several variables that can be used to identify the bicycle-train traveller: age, social status, travel purpose, educational level, and gender. In order to map their travel behaviour, they were asked to provide their travel preferences: choice of station, choice of access/egress transport modes, and, when the transport mode choice was a bicycle, choice of type of bicycle. The behaviour on both the home-end and activity-end of the train trip was mapped. Whereas past studies have looked at only one of the mentioned choices - see La Paix and Geurs (2015) for mode choice and Van Mil et al. (2018) for station choice - this study takes an integrated approach: analysing station choice, mode choice and the choice of the type of bicycle in one go.

Comparisons with the Dutch National Railways' passenger age data reveals that the average age of respondents was higher than the average age of the population. ${ }^{7}$ In order to account for the skewed age distribution and avoid the potential results bias, we analysed station choice, mode choice, and bicycle choice for each age cohort separately. We found that only mode choice differs between age classes; station choice and choice of type of bicycle did not. ${ }^{8}$

We employed descriptive analyses. This type of foundational analysis is still largely lacking in the nascent bicycle-train literature and is well suited for an explorative investigation of relationships in order to enable follow-up research with a more in-depth focus.

\footnotetext{
${ }^{6}$ Provided the Dutch national average of $43 \%$ cycling use in access travel and $14 \%$ in egress travel to/from rail stations (hence an indicative average of 30\%) in 2016, we chose to define everything below $15 \%$ as low, whereas everything above $50 \%$ is high, and everything in between is average, resulting in roughly three intensity groups of equal respondent size in the sample.

7 In our sample, the average age of the 'average bicycle-train traveller' and the 'frequent bicycle-train traveller' is 52 years old, while, according to NS' 2014 customer satisfaction data, the average age of train travellers using bicycles as an access mode was 33 years old.

${ }^{8}$ For an analysis of the age variable see Jonkeren et al. (2018, pp. 105-107).
} 


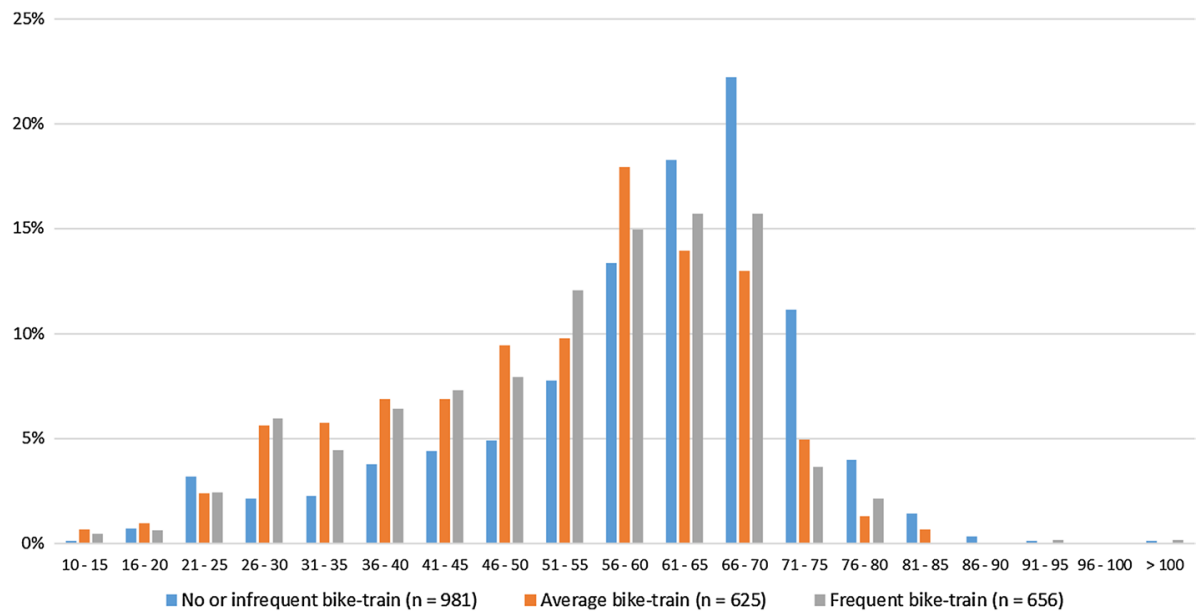

Fig. 1 Percentage of all travellers in three groups of varying bicycle-train usage per age category. Legend: no or infrequent use of bicycle-train (0-15\% bicycle share in access/egress); average bicycle-train usage (16-50\% bicycle share in access/egress); use bicycle-train frequently (more than $51 \%$ bicycle share in access/egress)

\section{Bicycle-train travellers: who are they?}

As shown in Fig. 1, the bicycle-train traveller (orange and grey bars) is generally younger than the train traveller who 'not at all or infrequently' combines train trips with cycling (blue bars). In addition, there are small differences between the 'average bicycle-train' and 'frequent bicycle train' groups in every age class.

Next, we examined the extent to which different categories of social status are represented in the sample (Fig. 2), distinguishing five categories: study/school, entrepreneur, salaried employment, (early) retired, and other. The 'salaried employment' category occupied a larger share in the 'average bicycle-train' and 'frequent bicycle-train' groups (almost $60 \%$ ) than in the 'not at all or infrequent' bike-train group (a bit less than $40 \%$ ). There were small differences in combined bicycle-train use in the 'study/school' and 'entrepreneur' categories. The bars for the 'entrepreneur' category indicate that the share of entrepreneurs in the 'frequent bike-train' group is somewhat larger than in the 'not at all or infrequent bike-train' group. Concurrently, the share for the '(early) retired' category is considerably lower in the 'average' and 'frequent' groups (18\% and 19\%, respectively) than in the 'not at all or infrequent' group (38\%). The 'other' category consists of persons with the status 'incapacitated for work', 'houseman/housewife', 'job seeker', 'I do voluntary work', or 'other'. In summary, the second characteristic of the bicycle-train traveller is that he or she is more likely to be engaged in salaried employment or be an entrepreneur than other train travellers. Please note that the shares of each cycling group in the different categories (for example the category 'Study/school') could be different if we would have had more young respondents. This is the result of the age bias. Therefore this conclusion should be taken with some restraint.

The respondents were also classified according to 'predominant travel purpose' (Fig. 3). The categorisation of 'predominant' reflects the respondent's self-reported dominant travel purpose when traveling by train and registering on the NS Panel; however, it does not necessarily reflect the reason for all train trips made during the two-week survey period. The 
$70 \%$

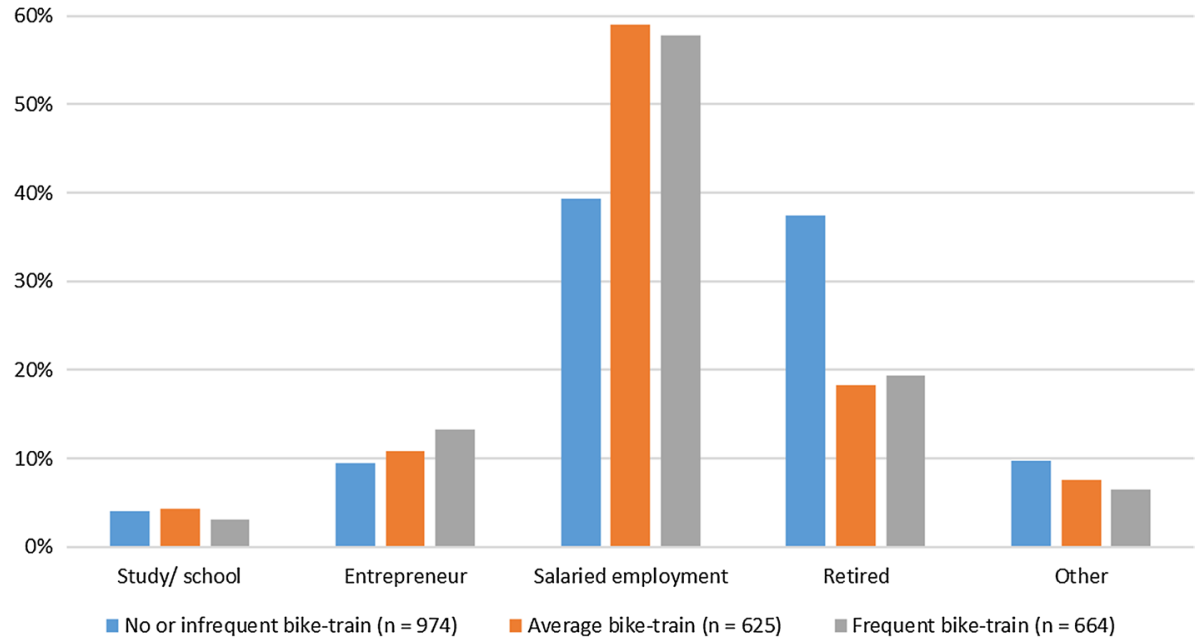

Fig. 2 Percentage of all travellers in three groups of varying bike-train usage per social status category. Legend: no or infrequent use of bicycle-train (0-15\% bicycle share in access/egress); average bicycle-train usage (16-50\% bicycle share in access/egress); use bicycle-train frequently (more than $51 \%$ bicycle share in access/egress)

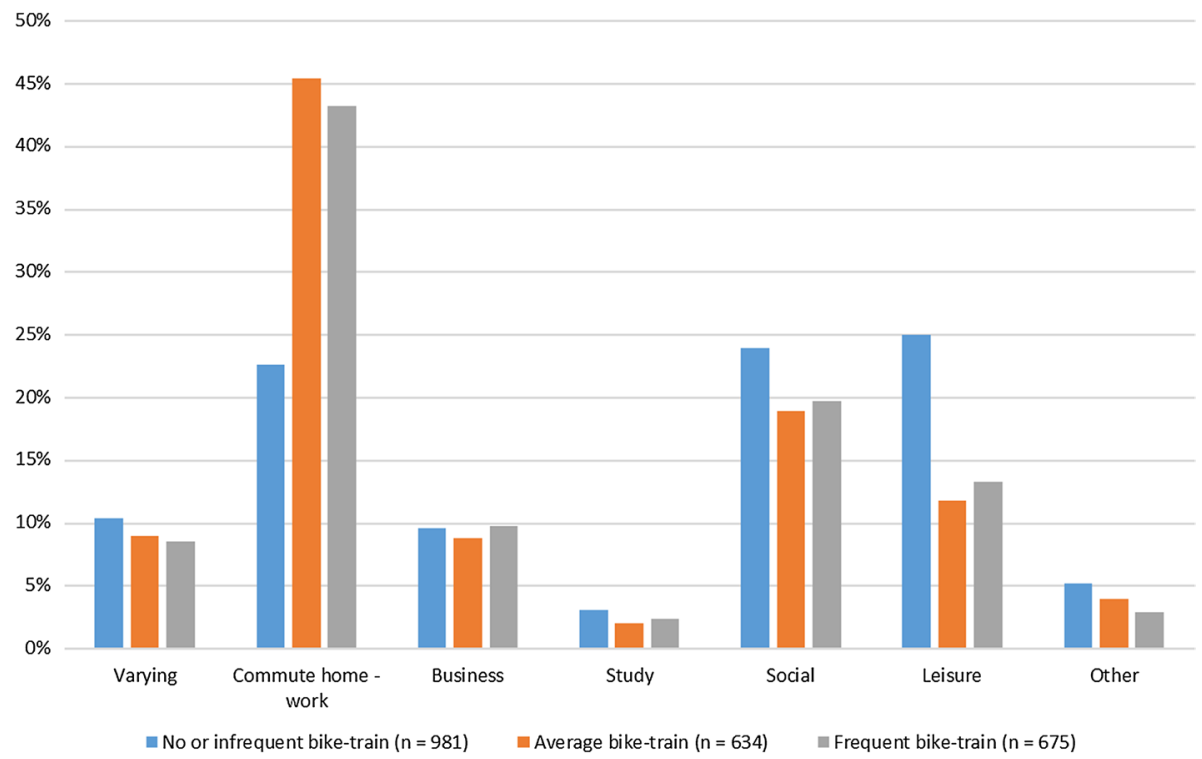

Fig. 3 Percentage of all travellers in three groups of varying bike-train usage per predominant travel motive category. Legend: no or infrequent use of bicycle-train (0-15\% bicycle share in access/egress); average bicycle-train usage (16-50\% bicycle share in access/egress); use bicycle-train frequently (more than $51 \%$ bicycle share in access/egress) 


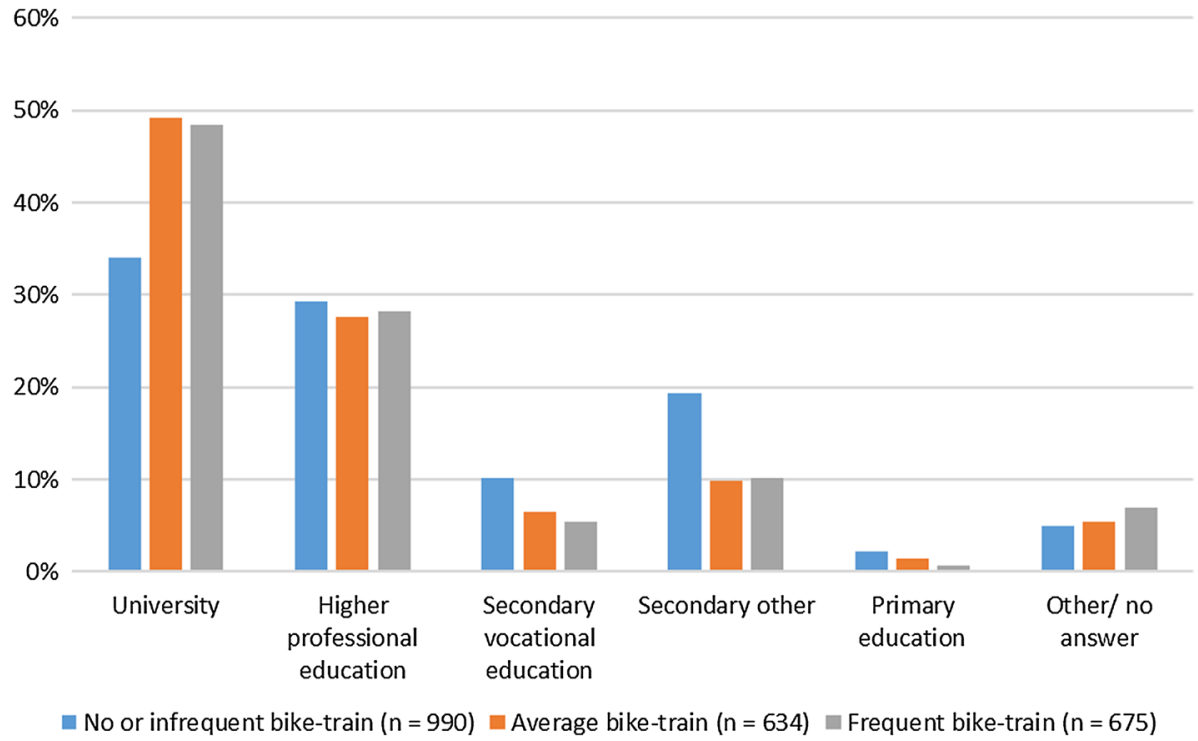

Fig. 4 Percentage of all travellers in three groups of varying bike-train usage per education level category. Legend: no or infrequent use of bicycle-train (0-15\% bicycle share in access/egress); average bicycle-train usage (16-50\% bicycle share in access/egress); use bicycle-train frequently (more than $51 \%$ bicycle share in access/egress)

home-work commute was by far the most common travel purpose for the 'average' and 'frequent' bicycle-train groups ( $46 \%$ and $43 \%$, respectively). Travelers with a businessrelated reason, people who study, and people with varying travel purposes claimed more or less equal shares in the three groups. The 'social' and 'leisure' categories claimed a larger share of respondents in the 'not at all or infrequent bicycle-train' group than in the other groups. In summary, for all bicycle-train travellers the largest share stated commuting between home and work as the primary travel purpose,${ }^{9}$ compared to the non-cycling train travellers. Like with the previous characteristic, also the conclusion for 'predominant travel motive' should be interpreted with some care.

Figure 4 shows the distribution according to educational level. The bicycle-train travellers (orange and grey bars) are particularly distinguished by the fact that they are more likely to hold university degrees than the group of train passengers who cycle not at all or infrequently (grey bars). The 'higher professional education' category is more or less equally represented in all three groups. Except for 'other/no answer', all other categories (i.e. those with lower education levels) have a lower share in the 'average' and 'frequent' bicycle-train groups than in the group that primarily uses other modes of transport for access and egress. Hence, the bicycle-train traveller is on average highly educated.

\footnotetext{
9 As the vertical axis represents percentages, one cannot conclude that the 'average' and 'frequent' bicycletrain travellers make fewer leisure trips than the 'not at all and infrequent' bicycle-train travellers. It is possible that the absolute number of leisure trips made by typical bicycle-train travellers in the home-work commuter category is higher than the absolute number of leisure trips made by the "not at all and infrequent' group in the leisure category.
} 
Table 2 Station typology of the Dutch National Railways

\section{Location}

City centre City border and Peripheral area

suburbs

Service status

High speed trains, intercity trains, sprinter 1 trains

Intercity trains and sprinter trains $\quad 2$

Sprinter trains 4

5

6

Source: Van Hagen and de Bruyn (2002)

Regarding the final characteristic, 'gender', $47 \%$ of the bicycle-train traveller group were men and $50 \%$ women, with $3 \%$ of respondents not indicating their gender. Of the group that made a train trip but did not cycle, $46 \%$ were men, $52 \%$ women, and $2 \%$ did not denote their gender.

Looking at all results presented in this section, the respondents in the 'not at all or infrequent' group clearly differ from the respondents in the 'average' and 'frequent' groups. Respondents in the 'average' and 'frequent' groups share very similar characteristics, supporting our decisions to typify respondents in both groups as 'bicycle-train travellers'. Compared to the 'not at all or infrequent' group, the bicycle-train travellers are on average more likely to be young people who are engaged in full-time employment or entrepreneurs, commute to work and hold university degrees. This profile matches the Shelat et al. (2018) characterisation of the combined bicycle-transit user.

\section{The bicycle-train traveller: what are their travel choices?}

This section focuses on the most important travel choices of the bicycle-train travellers, shedding light on their preferences and travel behaviour. Detailed knowledge about their travel preferences can provide useful inputs not only for policies that aim to further increase combined bicycle-train use in the Netherlands but also for informing policymaking in other cities and countries.

\section{Station choice}

Station choice is analysed on the aggregate level, i.e. on the level of station type rather than on the individual station level. The Dutch National Railways classifies its train stations into six categories, ranging from very large stations in large cities (type 1) to small stations in small towns (type 6). See Table 2 for a characterisation of the station types along two dimensions: location and service status.

Column two of Table 3 denotes the number of stations per station type in the Netherlands. Because our sample has a spatial focus on several large cities, it should not be inferred that the respondents used all 400 stations. The information in column two is only 
Table 3 Chosen and skipped station types by bicycle-train travellers

\begin{tabular}{|c|c|c|c|c|c|}
\hline \multicolumn{2}{|c|}{ Train station (according to NS classification) } & \multicolumn{2}{|c|}{$\begin{array}{l}\text { Station type chosen by } \\
\text { bicycle-train travellers at } \\
\text { home-end }\end{array}$} & \multicolumn{2}{|c|}{$\begin{array}{l}\text { Station type skipped by } \\
\text { bicycle-train travellers } \\
\text { at home-end }\end{array}$} \\
\hline Type of station & No. of stations ${ }^{\mathrm{a}}$ & No. of trips & $(\%)$ & No. of trips & $(\%)$ \\
\hline 1. Very large station in city centre & 6 & 2439 & 49 & 155 & 3 \\
\hline $\begin{array}{l}\text { 2. Large station in medium-sized } \\
\text { city }\end{array}$ & 30 & 510 & 10 & 52 & 1 \\
\hline $\begin{array}{l}\text { 3. Suburban station with hub func- } \\
\text { tion }\end{array}$ & 11 & 1061 & 21 & 632 & 13 \\
\hline $\begin{array}{l}\text { 4. Medium-size station in centre of } \\
\text { small town or village }\end{array}$ & 147 & 363 & 7 & 392 & 8 \\
\hline $\begin{array}{l}\text { 5. Suburban station without node } \\
\text { function }\end{array}$ & 110 & 490 & 10 & 3181 & 67 \\
\hline $\begin{array}{l}\text { 6. Station in rural small town or } \\
\text { village }\end{array}$ & 96 & 83 & 2 & 330 & 7 \\
\hline Total & 400 & 4947 & 100 & 4742 & 100 \\
\hline
\end{tabular}

a Source: NS passengers, station classification (as per 30 Nov 2015)

meant to provide a general indication of the distribution of stations in the Netherlands across the six categories.

Table 3 shows the extent to which bicycle-train travellers choose and skip the various station types. Here, the unit of measurement is 'trips', not respondents. Respondents reported the stations they used in the observed two weeks (with a maximum of five stations) and ranked them based on frequency of use. The number of train trips was then distributed over the stations on the basis of the following weights: 100:50:30:25:20, so that the most used station has the largest weight. Out of a total of 4947 trips to a home-end station, a type 1 station was chosen 2439 times. A 'skipped' train station is defined as a station situated closer to the respondent's residential location ${ }^{10}$ than the chosen station. ${ }^{11}$ To determine the proximity of train stations, the distance (in a straight line) between the centroid of the 4-digit postcode of the respondent's residential location and each railway station was calculated. The group of type 1 stations contains only six stations: Amsterdam Central, Utrecht Central, Rotterdam Central, The Hague Central, Eindhoven, and Amsterdam Airport Schiphol. Because virtually no one resides in the vicinity of Amsterdam Airport Schiphol, the values for station type 1 actually relate to only five stations. A type 1, 2 or 3 station was chosen $80 \%$ of the time, while conversely a type 1, 2 or 3 station was only skipped $17 \%$ of the time. This occurred at the expense of mainly type 5 stations, demonstrating that higher tier stations attract cyclists from a wider catchment area and that cyclists who live at a cyclable distance from these stations-especially type 1 and 2 almost always choose this station type. Table 3 also shows that the group of type 5 stations has by far the largest share of the total number of times that stations were skipped, which

\footnotetext{
10 The respondent's residential location is known on the 4-digit postal code level.

11 Please note that, according to this definition, a 'skipped' station is not necessarily literally passed by the traveller while cycling to a higher tier station. It can be also located in the opposite direction of travel. All distances are measured in a straight line.
} 
can be explained by the fact that this station type is often situated in or near residential areas at the edge of large cities. Many cyclists do not choose these stations as their homeend stations even when they are situated close by, preferring instead to cycle to a more distant but larger station. The general conclusion is that bicycle-train travellers prefer to cycle further to avoid the need to transfer trains. This finding is in line with the stated preference study of Van Mil et al. (2018), who concluded that a bicycle-train traveller is willing to cycle 5 additional minutes in order to avoid a transfer, and Nieves (2018), who showed that 'train-cyclists' in the Amsterdam metropolitan area are willing to take longer cycling journeys in order to shorten their train trips. In addition, higher tier stations offer better services in terms of train schedules (more frequent train connections and more choices of the fast intercity trains) and facilities (bicycle parking, shops, toilets, etc.) than lower tier stations.

\section{Activities during bicycle-train travel to/from train stations}

Table 4 provides information about the 'trip chaining' that occurs during the bicycle leg of the bicycle-train trip. Knowledge about the extent to which bicycle-train travellers are involved in trip chaining is relevant because it indicates the ease with which this can take place. In the current context, trip chains describe how bicycle-train travellers link their travels between 'significant' locations (e.g. home and work location or location of a leisure activity) and undertake the activities listed in Table 4. It appears that visiting supermarkets (41\%), visiting other shops (28\%), posting letters, and withdrawing money from ATMs (28\%) are the most popular activities for trip chaining on the bicycle leg. The bicycle might be an important enabler for trip chaining. Already in 2000, Hensher and Reyes (2000) concluded that complex trip chains require flexible travel modes. The bicycle is such a flexible travel mode (along with walking). This conclusion is supported by the fact that at most $15 \%$ of the bicycle-train travellers in our sample were not involved in an activity at least one time during the observed two-week period.

\section{Mode choice}

Table 5 (home-end) and Table 6 (activity-end) present the mode shares based on the estimated number of trips per mode that the respondents made during the 2 weeks prior

Table 4 Activities of bicycle-train travellers on their way to/from train stations

\begin{tabular}{ll}
\hline Activity & $\begin{array}{l}\text { Share (\%) of } \\
\text { bicycle-train travellers } \\
(\mathrm{n}=1309)\end{array}$ \\
\hline Visiting a supermarket & 41 \\
Visiting a shop (other than a supermarket) & 28 \\
Posting a letter or withdrawing money from an ATM & 28 \\
Visiting a restaurant/bar & 20 \\
Other or no activity & 15 \\
Visiting a service provider (e.g. dentist, hairdresser) & 9 \\
Pick up/delivery of parcel or goods & 8 \\
Bringing/fetching children from day care & 5 \\
\hline
\end{tabular}

Remark: The activity was carried out at least once during the observed two-week period 
Table 5 Mode choice at home-end of the train trip

\begin{tabular}{lllllllr}
\hline Region & $\begin{array}{l}\text { Walking } \\
(\%)\end{array}$ & $\begin{array}{l}\text { Bicycle } \\
(\%)\end{array}$ & $\begin{array}{l}\text { BTM } \\
(\%)\end{array}$ & $\begin{array}{l}\text { Car (driver) } \\
(\%)\end{array}$ & $\begin{array}{l}\text { Car (pas- } \\
\text { senger) } \\
(\%)\end{array}$ & $\begin{array}{l}\text { Other } \\
(\%)\end{array}$ & No. of trips \\
\hline Amsterdam & 17 & 51 & 30 & 0 & 1 & 1 & 2027 \\
Rotterdam & 27 & 39 & 29 & 3 & 1 & 2 & 1120 \\
Utrecht & 25 & 55 & 19 & 0 & 1 & 0 & 2093 \\
Eindhoven & 12 & 50 & 30 & 4 & 2 & 2 & 513 \\
$\begin{array}{l}\text { Other towns in } \\
\text { the Netherlands }\end{array}$ & 20 & 56 & 11 & 11 & 1 & 1 & 1491 \\
Total & 21 & 51 & 23 & 3 & 1 & 1 & 7244
\end{tabular}

Remarks: BTM (Bus/Tram/Metro); Other includes scooter, ferry etc.; No. of trips are no. of respondents $\times$ trips per respondent

Table 6 Mode choice at activity-end of the train trip

\begin{tabular}{llllllll}
\hline Region & $\begin{array}{l}\text { Walking } \\
(\%)\end{array}$ & $\begin{array}{l}\text { Bicycle } \\
(\%)\end{array}$ & $\begin{array}{l}\text { BTM } \\
(\%)\end{array}$ & $\begin{array}{l}\text { Car (driver) } \\
(\%)\end{array}$ & $\begin{array}{l}\text { Car (pas- } \\
\text { senger) } \\
(\%)\end{array}$ & $\begin{array}{l}\text { Other } \\
(\%)\end{array}$ & No. of trips \\
\hline Amsterdam & 51 & 15 & 32 & 0 & 1 & 1 & 1538 \\
Rotterdam & 45 & 14 & 35 & 0 & 2 & 4 & 635 \\
Utrecht & 51 & 21 & 25 & 0 & 2 & 1 & 885 \\
Eindhoven & 51 & 22 & 22 & 0 & 5 & 1 & 194 \\
$\begin{array}{l}\text { Other towns in } \\
\text { the Netherlands }\end{array}$ & 51 & 20 & 23 & 0 & 4 & 2 & 3992 \\
Total & 51 & 20 & 23 & 0 & 4 & 1 & 7244
\end{tabular}

Remarks: BTM (Bus/Tram/Metro); Other includes scooter, ferry etc.; No. of trips are no. of respondents $\times$ trips per respondent

to completing the survey. The number of trips per mode is an estimate, due to the fact that while the mode is reported by the respondents, the frequency how often this particular mode was used to travel to/from the station during the two-week period is not. If more than one mode was used, it is assumed that each was used equally often. If for example a respondent used the train on four days and indicated that both the bicycle and BTM (Bus, Tram, Metro) were used, each mode is assumed to be used twice. The mode shares are thus weighted for the number of train trips made. The transport modes most often chosen on the home-end and activity-end are walking, cycling and BTM. Cycling claimed a much larger share at the home-end than at the activity-end, which is likely due to bicycles being less-readily available on the activity-end. At the activity-end, train travellers rely on public transport bicycles (PT-bicycles), folding bicycles and private bicycles (also called 'second bicycles') permanently parked at an activity-end train station. Walking shows the precise opposite distribution than for bicycles: walking claims a high share on the activity-end and much lower share on the home-end. BTM's share is approximately equal on both ends of the train trip. Regarding the location, cycling's share on the home-end in Rotterdam stands out as being significantly lower (39\%) than 
in other urban regions and in the rest of the Netherlands ('Other towns in the Netherlands'). Concurrently, Rotterdam had a relatively high share for walking. The $11 \%$ for car use (as a driver) on the home-end for 'Other towns in Netherlands' is plausible, as the category includes trips to/from stations in semi-urban and rural areas alike, marked by lower accessibility to BTM, longer cycling distances to stations than in urban areas, and car parking facilities that are generally easily accessible, free of charge and of sufficient capacity (unlike most train stations in urban areas).

Figure 5 shows the relationship between the degree of bicycle use (to/from train stations, home-end and activity-end) and train use during the two-week study period. People who frequently travel by train also cycle relatively more frequently to/from train stations than people who rarely travel by train. Although the share of 'frequent bicycle-train' increases somewhat as the number of train days increases, the trade-off is primarily between the 'not at all or infrequent bicycle-train' and 'average bicycle-train' groups.

\section{Choice of type of bicycle}

Table 7 (home-end) and Table 8 (activity-end) present the shares of the different types of bicycles. The shares are weighted according to the respondent's frequency of bicycle use. Consequently, a respondent who indicated that he or she used a certain type of bicycle for 6 days has double the weight of a respondent who used that type of bicycle for 3 days. The tables consider six types of bicycles. The PT-bicycle (OV-fiets in Dutch) is a bikesharing system operated by the Dutch National Railways, allowing train travellers to rent bicycles (which are primarily used at activity-end stations). Folding bicycles are compact bicycles that can be taken on board of trains free of charge. Regular bicycles are standard Dutch-style bicycles. Electric bicycles (or e-bikes) have electric-powered support, allowing cyclists to travel longer distances or cycle faster. Special types of bicycles include mountain bikes, racing bikes, cargo bikes and recumbent bicycles.

The general picture is that regular bicycles claim a higher share on the home-end than on the activity-end. On the activity-end, major differences exist between regions. As the number of respondents travelling to Eindhoven and Rotterdam and using bicycles there

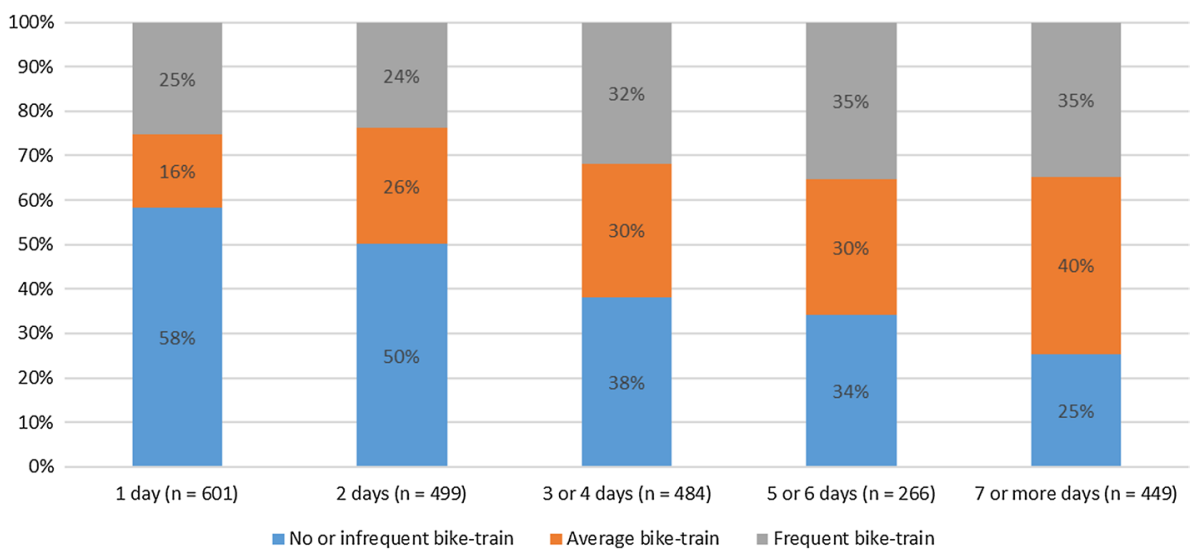

Fig. 5 Bicycle-train use and train intensity. Legend: no or infrequent use of bicycle-train (0-15\% bicycle share in access/egress); average bicycle-train usage (16-50\% bicycle share in access/egress); use bicycletrain frequently (more than $51 \%$ bicycle share in access/egress). The horizontal axis denotes the number of days trains were used during the studied two-week period 
Table 7 Choice of type of bicycle on home-end of train trip

\begin{tabular}{|c|c|c|c|c|c|c|c|}
\hline \multirow[t]{2}{*}{ Region } & \multirow{2}{*}{$\begin{array}{l}\text { No. of } \\
\text { respondents }\end{array}$} & \multicolumn{6}{|c|}{ Type of bicycle } \\
\hline & & $\begin{array}{l}\text { Regular } \\
(\%)\end{array}$ & $\begin{array}{l}\text { Electric } \\
(\%)\end{array}$ & $\begin{array}{l}\text { PT-bicycle } \\
(\%)\end{array}$ & $\begin{array}{l}\text { Folding } \\
(\%)\end{array}$ & $\begin{array}{l}\text { Special } \\
(\%)\end{array}$ & $\begin{array}{l}\text { Other } \\
(\%)\end{array}$ \\
\hline Amsterdam & 386 & 88 & 2 & 1 & 7 & 2 & 0 \\
\hline Rotterdam & 134 & 84 & 3 & 1 & 7 & 5 & 0 \\
\hline Utrecht & 325 & 88 & 2 & 1 & 5 & 3 & 1 \\
\hline Eindhoven & 91 & 76 & 3 & 2 & 11 & 7 & 0 \\
\hline $\begin{array}{l}\text { Other towns in } \\
\text { the Netherlands }\end{array}$ & 273 & 87 & 4 & 0 & 8 & 1 & 0 \\
\hline Total & 1209 & 87 & 4 & 0 & 7 & 2 & 0 \\
\hline
\end{tabular}

Remarks: Regular includes city bicycle, station bicycle, bicycles of 'normal' size; Special includes racing bicycle, mountain bicycle, recumbent bicycle, etc

Table 8 Choice of type of bicycle on activity-end of train trip

\begin{tabular}{|c|c|c|c|c|c|c|c|}
\hline \multirow[t]{2}{*}{ Region } & \multirow{2}{*}{$\begin{array}{l}\text { No. of } \\
\text { respondents }\end{array}$} & \multicolumn{6}{|c|}{ Type of bicycle } \\
\hline & & $\begin{array}{l}\text { Regular } \\
(\%)\end{array}$ & $\begin{array}{l}\text { Electric } \\
(\%)\end{array}$ & $\begin{array}{l}\text { PT-bicycle } \\
(\%)\end{array}$ & $\begin{array}{l}\text { Folding } \\
(\%)\end{array}$ & $\begin{array}{l}\text { Special } \\
(\%)\end{array}$ & $\begin{array}{l}\text { Other } \\
(\%)\end{array}$ \\
\hline Amsterdam & 72 & 73 & 0 & 13 & 10 & 3 & 0 \\
\hline Rotterdam & 33 & 66 & 1 & 12 & 21 & 0 & 0 \\
\hline Utrecht & 64 & 26 & 1 & 44 & 26 & 2 & 1 \\
\hline Eindhoven & 14 & 21 & 0 & 14 & 65 & 0 & 0 \\
\hline $\begin{array}{l}\text { Other towns in } \\
\text { the Netherlands }\end{array}$ & 295 & 56 & 1 & 23 & 17 & 2 & 0 \\
\hline Total & 478 & 55 & 1 & 23 & 18 & 2 & 0 \\
\hline
\end{tabular}

Remarks: Regular includes city bicycle, station bicycle, bicycles of 'normal' size; Special includes racing bicycle, mountain bicycle, recumbent bicycle, etc. The percentages relate to the choices made in the area. For example, from the 72 respondents who cycle at the activity-end of a train station in Amsterdam, $73 \%$ used a regular bicycle. Those respondents reside somewhere else than in the Amsterdam region

on the activity-end is low, reliable conclusions cannot be drawn for these groups. The use of PT-bicycles and folding bicycles on the activity-end is high in Utrecht compared to the other areas. The figures for these bicycle types (home-and and activity-end and all regions) are higher than expected based on the 'cycling knowledge' of the authors. Consequently, it could be that people who own folding bicycles had a higher response rate.

\section{Discussion of results and lessons for policymaking}

Compared to train travellers who hardly or never use bicycles to travel to/from train stations, bicycle-train users are on average more likely to be young people who are engaged in full-time employment or entrepreneurs, commute to work and hold university degrees. In addition, there seems to exist a positive relationship between the percentage of bicycle 
use in access and egress travel and the level of train use. ${ }^{12}$ In line with this observation, we found that bicycle-train travellers frequently are also train commuters (as train commuting is usually a recurring activity). This last observation corresponds to the findings of Givoni and Rietveld (2007) in their study of access to railway stations in the Netherlands.

Looking at age, there are several possible reasons why bicycle-train travellers tend to be young. Young people tend to have busier lives, spending more time in and around cities. Consequently they have a greater need for efficient transport modes, like bicycle-train transit that is geared towards cities. Moreover, they are on average more physically fit, which, on the one hand, removes a barrier and, on the other, can even provide an incentive (e.g. a light workout as a daily routine) for the bicycle-train combination. The described profile of bicycle-train travellers is useful for demarcating the target group of potential bicycle-train travellers for policymakers in countries and cities where the combined use of bicycle and train is still in its infancy.

Regarding the bicycle-train travellers' choice of station, it appears that they emphatically skip suburban stations without a node function (type 5 stations), frequently choosing very large stations in the centres of large or medium-sized cities (type 1 and 2 stations). These stations offer relatively good rail services (intercity connections in many directions, restaurants and shops) as well as bicycle parking services (guarded, free parking, close to platforms). At type 5 stations the rail and bicycle parking services are much poorer; intercity trains do not stop there, and there is no free, guarded bicycle parking available. The conclusion is that there seems to be a trade-off between cycling distance and station service quality. Consequently, a key point in the context of policy learning is that bicycletrain travellers are willing to cycle longer distances in order to avoid having to transfer between two trains and to access higher quality service locations. Moreover, it seems that due to its flexibility, the bicycle — and thus the bicycle-train combination-is well suited for trip chaining. Regarding mode choice, a key observation is that bike-sharing is much more prevalent on the activity-end of train trips than on the home-end. This seems to imply that there is a large latent demand for bicycle use on the activity-end, which is currently limited due to the comparatively low availability of bicycles on that end of the train trip. If the supply of shared bicycles on the activity-end was improved, bicycle use would also perhaps increase on the activity-end of train trips. This would add similar flexibility, allowing travellers to personalise their entire trips, rendering the bicycle-train combination even more attractive. Furthermore, bike-sharing on the activity-end is low in the major cities of Rotterdam and Amsterdam, compared to the other areas. One reason for this finding could be that both cities have highly developed metro networks, as well as relatively long average access/egress distances to stations, owing to their larger geographical sizes. This could have a dampening effect, preventing travellers from taking advantage of the various options for bicycle use on the activity-end: PT-bicycles, folding bicycles and second bicycles. Such insights could prove valuable for other cities that have extensive public transport networks and would like to encourage bicycle use for access and egress trips to/from train stations. A key finding regarding the choice of type of bicycles is that regular bicycles claim by far the largest share on the home-end. This can be explained by the fact that virtually everyone in the Netherlands owns a bicycle that they store at home. Another observation is that

\footnotetext{
12 A possible explanation is that minimising waiting times at stations is more important for high-frequency train travellers than for people who rarely travel by train. When using bicycles, waiting times at stations can be planned to a high degree and attuned to personal or contextual preferences. This does not usually work with buses, trams or metro as access and egress modes.
} 
PT-bicycles claim a considerable share on the activity-end, and, because PT-bicycles are shared bicycles that must be picked up/dropped off at train stations, it further emphasises the potential of bike-sharing systems to increase bicycle use on the activity-end. This is a key point for consideration by policymakers in the field of active and public transport.

\section{Limitations and further research}

Several limitations to this research should be noted. First, we had to estimate the data for combined bicycle-train use on the trip level. In the survey, the respondents reported on the stations, modalities and bicycle types used during the two-week study period. The survey also produced data on the number of train trips in this period. However, in order to render the questionnaire easier to complete and in line with this study's aims, the questionnaire only asked for the various choices by binary categories, rather than by specification on the trip level. This limitation was overcome by estimating the frequency as based on weights (for stations) or an equal distribution over the trips (for access and egress modes and bicycle types). ${ }^{13}$

Another drawback was that older train travellers were overrepresented in our sample. Nonetheless, for station choice and choice of type of bicycle, there were practically no differences between the age classes.

Third, we would like to stress that this piece of research is an initial, broad investigation by means of descriptive statistics, aiming to enable follow-up research with a more in-depth focus on one or two of the key issues (e.g. station choice) addressed here.

Lastly, there are several reasons why the percentages for PT-bicycles and folding bicycles (on both the home-end and activity-end) were larger than expected. First, the use of folding bicycles (and also PT-bicycles) is perhaps more popular under travellers registered on the NS Panel (self-selection), the basis for the sample. Second, the willingness to participate in the survey was perhaps higher among PT-bicycle and folding bicycle users.

The absolute number of bicycle-train travellers with an electric bicycle in our sample is low. The overall group of people using an electric bicycle is increasing fast though. In $2018,40 \%$ of all newly sold bicycles in the Netherlands were electric bicycles (Nieuws. $\mathrm{nl}$ 2019). Especially for longer distances, electric bicycles offer an attractive solution for travel to/from train stations. This may indicate the existence of a completely new group of bicycle-train travellers: the electric bicycle-train traveller. A direction for further research could be to investigate the size and characteristics of this group, in order to identify their profiles and service needs at railway stations.

We should acknowledge that the behaviour of the bicycle-train traveller is largely a bottom-up phenomenon: the transport system in the Netherlands is not integrally planned to facilitate or promote such behaviour. While it is true that transit planners are aware of and plan for cyclists who arrive and depart from stations and that the key destination stations for urbanites are well known, the synergies described above are largely unplanned. This raises the question whether top-down planning could recreate these emergent characteristics. Do we need a combined planning department for the bicycle-train system? And, if so, on what level of government should it operate, since it connects locations on different spatial scales?

${ }^{13}$ For more details please consult the sections on station choice, mode choice and choice of type of bicycle. 
Finally, a key question to consider is how does this notion of a new, distinct mobility system with clear synergetic characteristics translate into discussions about how transport modes influence our spatial and social environments. Currently, such discussions mainly see car, transit and active modes (mostly walking) as co-evolving with distinct 'urban fabrics' (Newman et al. 2016). While attempts have been made to also define cycling-oriented development patterns, the bicycle-train combination would be a completely new construct. In the Netherlands, the bicycle-train combination has co-evolved with a spatial pattern that seems quite unique by international comparison-bundled deconcentration, or clustered suburbanisation (Janssen-Jansen 2016). The Netherlands' overall high density, yet with local pockets of dense and diverse urban cores around a set of transit nodes, has led some researchers to label the Netherlands not as a high-density country but rather as one large empty city. How these spatial patterns impact the potential contributions of the bicycletrain system (e.g. allowing for easy trip chaining) remains to be studied in greater detail.

This study is a step towards fully understanding the intricacies of the bicycle-train system. Further advances along the outlined future research directions would provide valuable insights into the success factors of this example of Dutch sustainable mobility innovation and its potential for application in other contexts.

Acknowledgements We would like to thank the participants of the 1st annual Cycling Research Board (CRB) conference, held in Amsterdam 14-16 November 2018, for their helpful comments and remarks. In addition, we are grateful to the Dutch National Railways for allowing us to use the NS Panel to obtain the data for this research study.

Author contributions Olaf Jonkeren: Data acquisition and questionnaire design, analytical setup, empirical analyses, manuscript writing. Lucas Harms: Questionnaire design, literature search and review, manuscript writing. Marco te Brömmelstroet: Manuscript writing, manuscript structure and critical revision. Roland Kager: Data acquisition and questionnaire design, analytical setup, empirical analyses and critical revision.

\section{Compliance with ethical standards}

Conflict of interest On behalf of all authors, the corresponding author states that there is no conflict of interest.

Open Access This article is distributed under the terms of the Creative Commons Attribution 4.0 International License (http://creativecommons.org/licenses/by/4.0/), which permits unrestricted use, distribution, and reproduction in any medium, provided you give appropriate credit to the original author(s) and the source, provide a link to the Creative Commons license, and indicate if changes were made.

\section{References}

Brons, M., Givoni, M., Rietveld, P.: Access to railway stations and its potential in increasing rail use. Transp. Res. Part A: Policy Pract. 43(2), 136-149 (2009)

Cervero, R., Caldwell, B., Ceullar, J.: Bicycle-and-ride: build it and they will come. J. Public Transp. 16(4), 83-105 (2013)

Dell'Olio, L., Ibeas, A., Cecin, P.: The quality of service desired by public transport users. Transp. Policy 18(1), 217-227 (2011)

Environmental Assessment Agency: http://www.pbl.nl/sites/default/files/cms/publicaties/PBL-2016-Citie s-in-Europe-2469.pdf

Fishman, E.: Cycling as transport. Transp Rev 36(1), 1-8 (2016)

Fleming, S.: How the Dutch do it: fewer train stations with bicycle-centric catchments, blogpost on http:// cycle-space.com/fiets-professor/ (2016) 
Geurs, K.T., La Paix, L., Van Weperen, S.: A multi-modal network approach to model public transport accessibility impacts of bicycle-train integration policies. Eur. Transp. Res. Rev. 8(4), 1-15 (2016)

Givoni, M., Rietveld, P.: The access journey to the railway station and its role in passengers' satisfaction with rail travel. Transp. Policy 14, 357-365 (2007)

Harms, L., Bertolini, L., Te Brommelstroet, M.: Spatial and social variations in cycling patterns in a mature cycling country exploring differences and trends. J. Transp. Health 1, 232-242 (2014)

Harms, L., Bertolini, L., Te Brommelstroet, M.: Performance of municipal cycling policies in mediumsized cities in the Netherlands since 2000. Transp. Rev. 36(1), 134-162 (2016)

Heinen, E., Buehler, R.: Bicycle parking: a systematic review of scientific literature on parking behaviour, parking preferences, and their influence on cycling and travel behaviour. Transp. Rev. 39(5), 630-656 (2019)

Hensher, D.A., Reyes, A.J.: Trip chaining as a barrier to the propensity to use public transport. Transportation 27, 341-361 (2000)

Hoogendoorn-Lanser, S., van Nes, R.: Home-activity approach to multi-modal travel choice modelling, contribution to Colloquium Vervoersplanologisch Speurwek 2005, Antwerp (2005)

Janssen-Jansen, L.: Taking national planning seriously: a challenged planning agenda in the Netherlands. Administration 64(3/4), 23-43 (2016)

Jonkeren, O., Harms, L., Jorritsma, P., Huibregtse, O., Bakker, P., Kager, R.: Where Would We Be Without the Bicycle and Train? Netherlands Institute for Transport Policy Analysis, KiM-18-A13, (in Dutch) (2018)

Kager, R., Bertolini, L., Te Brommelstroet, M.: Characterisation of and reflections on the synergy of bicycles and public transport. Transp. Res. Part A 85, 208-219 (2016)

Kager, R., Harms, L.: Synergies from Improved Bicycle-Transit Integration: Towards an Integrated Urban Mobility System. OECD/ITF, Paris (2017)

Keijer, M.J.N., Rietveld, P.: How do people get to the railway station? The Dutch experience. Transp. Plan. Technol. 23(3), 215-235 (2000)

Krizek, K., Stonebraker, E.: Bicycling and transit: a marriage unrealized. Transp. Res. Rec.: J. Transp. Res. Board 2144, 161-167 (2010)

La Paix, L., Geurs, K.: Modelling observed and unobserved factors in cycling to railway stations: application to transit-oriented-developments in the Netherlands. Eur. J. Transp. Infrastruct. Res. 15(1), 27-50 (2015)

Lee, J., Choi, K., Leem, Y.: Bicycle-based transit-oriented development as an alternative to overcome the criticisms of the conventional transit-oriented development. Int. J. Sustain. Transp. 10(10), 975-984 (2016)

Leferink, T.: Why cycle to the railway station? A station scanner based on factors that influence bicyclerail use. Delft: TU Delft/Witteveen \& Bos (Master thesis) (2017)

Martens, K.: Promoting bicycle-and-ride: the Dutch experience. Transp. Res. Part A 41(4), 326-338 (2007)

Menghini, G., Carrasco, N., Schussler, N., Axhausen, K.W.: Route choice of cyclists in Zurich. Transp. Res. Part A: Policy Pract. 44(9), 754-765 (2010)

Nello-Deakin, S., Harms, L.: Assessing the relationship between neighbourhood characteristics and cycling: findings from Amsterdam. Transportation Research Procedia (2019) (forthcoming)

Newman, P., Kosonen, L., Kenworthy, J.: Theory of urban fabrics: planning the walking, transit/public transport and automobile/motor car cities for reduced car dependency. Town Plan. Rev. 87(4), 429-458 (2016)

Nieuws.nl: Recordaantal e-bikes verkocht in 2018. Website consulted 10/05/2019: https://nieuws.nl/ algemeen/20190301/recordaantal-e-bikes-verkocht-in-2018/ (in Dutch) (2019)

Nieves, P.: How do train-cyclists navigate? Exploring bicycle-train route choice behaviour in the Amsterdam Metropolitan Area. Master thesis, University of Amsterdam (2018)

PBL: Cities in Europe: Facts and Figures on Cities and Urban Areas. PBL Netherlands (2016)

Pucher, J., Buehler, R.: Integrating bicycling and public transport in North America. J. Public Transp. 12(3), 79-104 (2009)

Rietveld, P.: The accessibility of railway stations: the role of the bicycle in The Netherlands. Transp. Res. Part D 5, 71-75 (2000)

Rietveld, P., Daniel, V.: Determinants of bicycle use: do municipal policies matter? Transp. Res. Part A: Policy Pract. 38(7), 531-550 (2004)

Shelat, S., Huisman, R., van Oort, N.: Analysing the trip and user characteristics of the combined bicycle and transit mode. Res. Transp. Econ. 69, 68-76 (2018)

Villwock-Witte, N., van Grol, L.: Case study of transit-bicycle integration. Transp. Res. Rec. 2534(1), $10-15(2015)$ 
van Mil, J., Leferink, T.S., Annema, J.A., van Oort, N.: Insights into factors affecting the combined bicycle-transit mode. In: CASPT 2018, Brisbane, Australia (2018)

van Hagen, M., de Bruyn, M.: Typisch NS. Elk station zijn eigen rol (in Dutch). In: CVS Conference 2002, Delft, The Netherlands (2002)

van Nes, R., Hansen, I., Winnips, C.: Potentie multimodaal vervoer in stedelijke regio's, Duurzame Bereikbaarheid Randstad—Notes for research and practice (2014)

Publisher's Note Springer Nature remains neutral with regard to jurisdictional claims in published maps and institutional affiliations.

Olaf Jonkeren is working as a senior researcher at KiM Netherlands Institute for Transport Policy Analysis. His research focuses on cycling and freight transport. He received a PhD in Transport Economics in 2009.

Roland Kager works as a data-analyst for Studio Bereikbaar in Rotterdam specializing in national travel survey data, public geodatabases and GPS-tracking data, focusing on the relationships between cycling, public transport and urbanity.

Lucas Harms is the Director of the Dutch Cycling Embassy. He has a background in urban geography and more than 15 years of research in various roles, focusing on urban planning and sustainable urban transportation.

Marco te Brömmelstroet holds the chair on Urban Mobility Futures at the University of Amsterdam. His research focuses on the reciprocal relations between mobility innovations and cities and society. 